\title{
Métodos biológicos para avaliar a brotação de gemas em macieira para modelagem da dormência
}

\section{Biological methods for assessment of budbreak in apple trees for modeling dormancy}

\author{
Rafael Anzanello ${ }^{1 *}$; Flávio Bello Fialho ${ }^{2}$; Henrique Pessoa dos Santos²; \\ Homero Bergamaschi ${ }^{3}$; Gilmar Arduino Bettio Marodin ${ }^{3}$
}

\begin{abstract}
Resumo
Um método biológico foi desenvolvido para caracterizar o estado de dormência de gemas de macieira, em condições controladas. Estacas (brindilas ou ramos de ano, com 20-25 cm) de 'Castel Gala' e 'Royal Gala' foram amostradas durante o período hibernal, avaliando-se diferentes regimes de frio e de calor para induzir a brotação. Testaram-se contrastes no processamento do material vegetal (estacas de nós isolados x intactas), na exposição ao frio para superação da dormência em câmaras incubadoras (plantadas em potes com espuma fenólica x embaladas em filme plástico, na posição vertical ou horizontal) e ao calor para indução da brotação em câmara de crescimento (base imersa em água $\mathrm{x}$ plantadas em espuma fenólica). Estacas intactas e em posição vertical durante o frio representaram melhor as condições de interação natural entre as gemas do que nós isolados, sendo a brotação das gemas laterais fortemente influenciada pela dominância apical. $\mathrm{O}$ acondicionamento das estacas em filme plástico, durante o frio, permitiu maximizar o espaço interno das incubadoras e o número de gemas em avaliação, em relação ao plantio de estacas em potes. No calor, estacas intactas em espuma fenólica apresentaram melhor conservação e sobrevivência das gemas ao longo do período de avaliação, se comparadas às que ficaram com bases imersas em água. As condições mais adequadas para avaliar a evolução do estado de dormência em gemas de macieira foram as que utilizaram estacas intactas embaladas na posição vertical durante os tratamentos de frio, com acompanhamento da brotação no calor após fixar as estacas em espuma fenólica. A padronização da metodologia contribui para obter melhores resultados no desenvolvimento de modelos fisiológicos da dormência.
\end{abstract}

Palavras-chave: Malus domestica, fisiologia vegetal, dominância apical

\begin{abstract}
A biological method was developed to evaluate the dormancy state of apple buds under controlled conditions. Cuttings (20-25 cm long) of 'Castel Gala' and 'Royal Gala' were sampled during the winter period, evaluating different cold and heat regimes to induce budbreak. Contrasts were tested in plant material processing (single node $\mathrm{x}$ intact cuttings), cold storage method to break dormancy in incubator chambers (planted in pots with floral foam $\mathrm{x}$ wrapped in plastic film, vertically or horizontally) and budbreak method in plant growth chambers (base immersed in water $\mathrm{x}$ planted in floral foam). Intact cuttings stored vertically in the cold represented better the natural interactions between buds than
\end{abstract}

\footnotetext{
${ }^{1}$ Eng $^{\text {os }_{\mathrm{S}}} \mathrm{Agr}^{\mathrm{os}_{\mathrm{s}}}$, Drs. Pesquisadores da Fundação Estadual de Pesquisa Agropecuária, FEPAGRO. RSC 470, Veranópolis, RS. E-mail: rafael-anzanello@fepagro.rs.gov.br

${ }^{2}$ Eng $^{{ }^{\mathrm{s}}} \mathrm{Agr}^{\mathrm{os}_{\mathrm{s}}}$, Drs. Pesquisadores da Empresa Brasileira de Pesquisa Agropecuária, EMBRAPA Uva e Vinho, Bento Gonçalves, RS. E-mail: flavio.bello@embrapa.br; henrique.p.santos@embrapa.br

${ }^{3}$ Eng $^{{ }^{\text {s }}}$ Agr $^{\text {os }}$, Drs. Bolsistas CNPq, Profs. Associados da Faculdade de Agronomia, Universidade Federal do Rio Grande do Sul, UFRGS, Porto Alegre, RS. E-mail: homerobe@ufrgs.br; marodin@ufrgs.br

* Autor para correspondência
} 
single node cuttings. Budbreak of lateral buds was strongly influenced by apical dominance. Wrapping cuttings in plastic film optimized internal space usage in the incubators and the number of evaluated buds, compared to planting cuttings in pots. During the warm period in the growth chambers, intact cuttings on floral foam resulted in better bud preservation and survival throughout the evaluation period, compared to cuttings with bases immersed in water. The most suitable conditions to evaluate dormancy evolution in apple buds used plastic-wrapped intact cuttings stored vertically during the cold period, with budbreak evaluation in the warm period after planting the cuttings in floral foam. Standardization of methodology helps to obtain better results in the development of physiological models of dormancy.

Key words: Malus domestica, vegetable physiology, apical dominance

\section{Introdução}

Em regiões temperadas e subtropicais, espécies frutíferas de clima frio, como a macieira, apresentam um período de dormência hibernal, com suspensão temporária do crescimento das plantas. Neste período, a dormência passa por três etapas: paradormência, endodormência e ecodormência (LANG et al., 1987). Na paradormência a ausência de desenvolvimento das gemas resulta da influência de outro órgão da planta, como a dominância apical. Na endodormência, a inibição da brotação é causada por eventos bioquímicos e fisiológicos no meristema ou tecidos próximos, pela percepção de um estímulo ambiental, normalmente por baixas temperaturas, fotoperíodo ou ambos. Este tipo de dormência pode ter duração e intensidade (profundidade) distintas, sendo superado pelo acúmulo de horas de frio no período de outono-inverno, e varia entre espécies e cultivares. Após a superação da endodormência, a brotação das gemas depende das condições de temperatura e disponibilidade hídrica, no estado denominado de ecodormência.

Estudos relacionados à dormência têm-se intensificado com a exploração comercial de frutíferas de clima temperado em regiões com menor disponibilidade de frio (DENNIS JUNIOR, 2003). Pela restrição de frio hibernal, problemas associados ao metabolismo de gemas se manifestam com frequência (JACKSON, 2003). Além disso, pesquisas sobre dormência adquirem maior relevância diante de cenários de mudanças climáticas globais, considerando possíveis incrementos na temperatura do ar e reduções na disponibilidade de frio hibernal (ANDRADE et al., 2012). No caso da macieira, tem-se buscado o emprego de modelos matemáticos para estimar o acúmulo de frio hibernal, como suporte ao manejo de pomares, principalmente pelo uso de produtos químicos para superação da endodormência. Entretanto, esses modelos não foram ajustados às condições climáticas do Sul do Brasil. Dentre suas deficiências, destacam-se a falta de ajuste das respostas das plantas às condições térmicas regionais e às especificidades de resposta a condições térmicas oscilantes (WEINBERGER, 1950; RICHARDSON; SEELEY; WALKER, 1974; SHALTOUT; UNRATH, 1983; EREZ; FISHMAN, 1990).

O conhecimento dos fatores e processos que afetam a dormência é essencial para desenvolver modelos relacionados à fisiologia das gemas durante o período hibernal e início da brotação. Para isto, são necessários métodos que reproduzam as condições de campo e possibilitem testes isolados para diferentes fatores (HAWERROTH et al., 2010). Em estudos desta natureza, há grande diversidade de estratégias e falta de padronização, que dificultam o entendimento dos mesmos e a avaliação dos efeitos de cada fator sobre o metabolismo das gemas (DENNIS JUNIOR, 2003), bem como a comparação de resultados para diferentes genótipos e condições experimentais. No campo, não há controle sobre radiação solar, precipitação e temperatura, sendo difícil determinar com precisão a necessidade de frio de espécies frutíferas, pela complexidade de interações que fatores de ambiente e planta exercem sobre a dormência (DENNIS JUNIOR, 2003). Assim, estudos em condições controladas são necessários, sobretudo envolvendo temperatura do ar (HAWERROTH et al., 2010). 
Os métodos biológicos se caracterizam pela observação fenológica direta (brotação e floração) em material vegetal submetido a condições controladas e distintas, durante a dormência (DOLE, 2001). Existem vários métodos biológicos, podendo-se utilizar plantas inteiras (em vasos ou ramos enxertados) ou apenas partes destas, tais como ramos destacados e nós isolados (HERTER, 1992; BALANDIER, 1992; CAMELATTO et al., 2000; CITADIN et al., 2001; WAGNER JUNIOR et al., 2006; CHAVARRIA; HERTER; RASEIRA, 2009). Os métodos que usam plantas inteiras permitem avaliar interações entre as gemas e outros tecidos ou órgãos, mas demandam grandes espaços em câmaras climatizadas e elevam os custos da pesquisa (HAWERROTH et al., 2010). Além disso, eles dificultam a aplicação de vários tratamentos térmicos, o que inviabiliza o ajuste de modelos precisos para estimar o estado de dormência. Em contrapartida, métodos que utilizam ramos destacados ou nós isolados possibilitam trabalhar com grande número de gemas em pequenos espaços, permitindo maior amplitude de resposta a diferentes condições térmicas. Contudo, a longevidade do material pode ser prejudicada, por desidratação dos tecidos vegetais (CITADIN; RASEIRA; QUEZADA, 1998). Assim, torna-se importante obter métodos cujo processamento e acondicionamento das estacas minimizem este problema.

O objetivo deste trabalho foi desenvolver um método de avaliação da dormência em gemas de macieira adequado à modelagem e previsão da brotação, no Sul do Brasil.

\section{Material e Métodos}

O material experimental para avaliar a evolução da dormência nos métodos biológicos utilizados consistiu de ramos de ano ou do ciclo anterior (brindilas) das cultivares Royal Gala e Castel Gala, que representam, respectivamente, genótipos de média e baixa exigência de frio hibernal (DENARDI;
SECCON, 2005; PETRI; PALLADINI; POLA, 2006). As brindilas foram amostradas com 20 a 25 $\mathrm{cm}$ de comprimento, apresentando em média oito gemas, em pomar comercial localizado no município de Papanduva - SC (26²6'68'S, 5005'47"W e $788 \mathrm{~m}$ de altitude). As amostragens foram feitas em diferentes épocas, no período de outono e inverno, em 2009, 2010 e 2011. Na seleção do material para coleta foram consideradas a maturidade das gemas (gemas bem fechadas), a sanidade (sem danos por Grapholita molesta B. ou outros danos sobre as escamas das gemas) e o vigor das estacas, priorizando aquelas com crescimento intermediário (cerca de $5 \mathrm{~mm}$ de diâmetro).

Após coletados no campo, os ramos foram enrolados em feixes, umedecidos, colocados em sacos plásticos e transportados para a Embrapa Uva e Vinho, em Bento Gonçalves - RS, para a avaliação da dormência das gemas em condições controladas. O tempo entre a coleta e o início do processamento das estacas foi o menor possível, nunca ultrapassando $24 \mathrm{~h}$. As estacas foram desfolhadas e processadas de duas formas: em estacas de nós isolados ou em estacas intactas. No método de estacas de nós isolados, as brindilas foram segmentadas em estacas com uma única gema apical ou lateral. As estacas com gema apical foram cortadas com $7 \mathrm{~cm}$ de comprimento, permanecendo somente a gema distal superior de cada brindila, sendo retiradas gemas laterais, eventualmente presentes na estaca. Para as estacas com gema lateral foi utilizada a parte intermediária do ramo, cortando-se uma extremidade em bisel, a aproximadamente $1 \mathrm{~cm}$ acima de uma gema lateral, e a outra extremidade $7 \mathrm{~cm}$ abaixo do primeiro corte, eliminando-se as demais gemas. No método de estacas intactas, as brindilas foram cortadas $20 \mathrm{~cm}$ abaixo da gema apical, de modo que mantivessem cerca de 6 a 10 gemas laterais.

O passo seguinte foi a desinfestação do material, em que, nos experimentos de 2009, as estacas foram submetidas à limpeza sequencial com etanol $70 \%$ por 60 a $90 \mathrm{~s}$, seguida de um enxágue com água 
destilada. Nos experimentos de 2010 e 2011, as estacas passaram por um processo de limpeza mais rigoroso, com etanol $70 \%$ por $45-60 \mathrm{~s}$, seguido de hipoclorito de sódio a $2,5 \%$ por 20 min e três enxágues com água destilada. Em seguida, as estacas foram secas à sombra, por aproximadamente $30 \mathrm{~min}$. Após a secagem, a extremidade superior das estacas de nós isolados com gemas laterais foi rapidamente mergulhada em parafina líquida para formar um filme protetor e diminuir a desidratação.

As estacas foram submetidas a regimes de frio constante $\left(3^{\circ} \mathrm{C}\right.$ ou $\left.6^{\circ} \mathrm{C}\right)$ ou alternado (ciclos diários de $3 / 15^{\circ} \mathrm{C}$ ) durante o período de dormência, em câmaras incubadoras climatizadas com controle de temperatura e fotoperíodo, da marca Eletrolab, modelo EL202. Periodicamente, as estacas foram transferidas para temperatura de calor $\left(25^{\circ} \mathrm{C}\right)$, em câmara de crescimento de plantas, da marca Percival Boone, modelo 50036, com dimensões de $4 \mathrm{~m}$ x 3m e 3,5m de altura e controle de temperatura, umidade e fotoperíodo, para indução e avaliação da brotação das gemas. As formas de preparo e condução do material durante o período de frio (para a superação da dormência) e durante o período de calor (para indução da brotação) utilizadas são mostradas na Tabela 1.

Tabela 1. Métodos de processamento e acondicionamento das estacas de macieira nos períodos de superação da dormência (frio) e brotação (calor).

\begin{tabular}{|c|c|c|c|c|}
\hline Metodologia & $\begin{array}{c}\text { Processamento } \\
\text { das estacas }\end{array}$ & $\begin{array}{l}\text { Gemas por } \\
\text { estaca }\end{array}$ & $\begin{array}{l}\text { Acondicionamento das } \\
\text { estacas no frio }\end{array}$ & $\begin{array}{l}\text { Acondicionamento das } \\
\text { estacas no calor }\end{array}$ \\
\hline NI & Estacas de nós isolados & 1 & $\begin{array}{l}\text { em potes com espuma } \\
\text { fenólica }\end{array}$ & $\begin{array}{l}\text { em potes com espuma } \\
\text { fenólica }\end{array}$ \\
\hline IP & Estacas intactas & 7 a 11 & $\begin{array}{c}\text { em potes com espuma } \\
\text { fenólica }\end{array}$ & $\begin{array}{l}\text { em potes com espuma } \\
\text { fenólica }\end{array}$ \\
\hline $\mathrm{EH}$ & Estacas intactas & 7 a 11 & $\begin{array}{c}\text { embaladas em filme plástico, } \\
\text { na horizontal }\end{array}$ & $\begin{array}{c}\text { em potes com espuma } \\
\text { fenólica }\end{array}$ \\
\hline VA & Estacas intactas & 7 a 11 & $\begin{array}{c}\text { embaladas em filme plástico, } \\
\text { na vertical }\end{array}$ & em plataforma com água \\
\hline $\mathrm{VE}$ & Estacas intactas & 7 a 11 & $\begin{array}{c}\text { embaladas em filme plástico, } \\
\text { na vertical }\end{array}$ & $\begin{array}{l}\text { em plataforma com espuma } \\
\text { fenólica }\end{array}$ \\
\hline
\end{tabular}

Fonte: Elaboração dos autores.

Após desinfestadas, as estacas de nós isolados foram plantadas em espuma fenólica previamente acondicionada em potes (Figura 1A). Os potes utilizados tinham volume de $300 \mathrm{ml}, 5 \mathrm{~cm}$ de altura, $10 \mathrm{~cm}$ de diâmetro de abertura e $8 \mathrm{~cm}$ de diâmetro de fundo. A espuma fenólica foi cortada com um molde de padaria para ter $8 \mathrm{~cm}$ de diâmetro e 3,75 $\mathrm{cm}$ de altura. A posição das estacas foi demarcada no lado superior da espuma com um molde feito com pregos, de modo que cada pote contivesse até 21 estacas, espaçadas em $1,5 \mathrm{~cm}$ entre si. Esses potes com estacas foram dispostos em seis prateleiras por câmara incubadora e submetidos a um período de frio.
As estacas intactas foram processadas de duas maneiras. Uma parcela foi plantada em espuma fenólica em potes e submetida a um período de frio, como no método de estacas de nós isolados (Figura 1B). Foram usadas no máximo 10 estacas por pote, para não dificultar a visualização das gemas. Outra parte das estacas intactas foi organizada em feixes de 20 unidades cada, embalados com filme plástico preto de polietileno, sendo identificada a posição da gema apical (Figura 1C). Os feixes foram colocados nas câmaras incubadoras no sentido horizontal ou vertical, mantendo, no caso vertical, a gema apical na posição superior. As estacas intactas foram acondicionadas em apenas três prateleiras nas 
incubadoras, devido à sua maior altura em relação às estacas de nós isolados.

Na câmara de crescimento, foram montadas duas mesas de madeira sobre as quais as estacas foram dispostas. As plantadas em potes foram transferidas diretamente para as bancadas, após o período de frio (Figura 1D). As embaladas foram desenroladas dos feixes e cortadas em bisel a $1 \mathrm{~cm}$ da extremidade inferior. As estacas foram acondicionadas de três maneiras: i) plantadas em potes com espuma fenólica (Figura 1D); ii) sustentadas por uma dupla camada de tela trançada $(1 \mathrm{~cm}$ x $1 \mathrm{~cm})$, sobre um reservatório com $3 \mathrm{~cm}$ de água (Figura 1E), com 5 $\mathrm{ml} \mathrm{L}^{-1}$ de hipoclorito de sódio (5\% de cloro ativo). A cada duas semanas, a água do reservatório era substituída e as estacas cortadas a $3 \mathrm{~mm}$ da extremidade basal, para evitar a obstrução do fluxo de seiva; iii) sustentadas por uma dupla camada de tela trançada $(1 \mathrm{~cm} \times 1 \mathrm{~cm})$, sobre uma plataforma de espuma fenólica umedecida com 3,75 cm de altura (Figura 1F), sem aditivos na água de irrigação ou procedimento periódico de corte das estacas.

As estacas em potes com espuma fenólica foram irrigadas a cada 96 h (nas câmaras incubadoras) ou 24 a 48 h (na câmara de crescimento), de modo a saturar a espuma fenólica, evitando o acúmulo de água livre nos potes. A água do reservatório e da plataforma de espuma fenólica era reposta a cada 48 a 72 h. A temperatura e a umidade do ar foram monitoradas através de um termo-higrógrafo e a umidade relativa foi mantida entre 70 a $80 \%$.

Nos experimentos de 2009, houve ocorrência de fungos (Botrytis e Fusarium), que foram controlados com aplicação de fungicidas à base de pirimetamil, iprodiona, captana e tebuconazol, a 1,5-2,0 $\mathrm{ml} \mathrm{L}^{-1}$ (os três primeiros) e $1,0 \mathrm{ml} \mathrm{L}^{-1}$ (tebuconazol), em frequência de 7 a 14 dias. Nos experimentos de 2010 e 2011, dispensaram-se tratamentos fitossanitários, devido à desinfestação inicial mais rigorosa com hipoclorito de sódio.

A avaliação da brotação das gemas foi realizada por fotografias diárias (Figura $1 \mathrm{G}$ e $1 \mathrm{H}$ ) ou por anotação manual diária, em planilhas. Para facilitar a fotografia de todas as gemas das estacas intactas, foram usados dois espelhos em ângulo de $120^{\circ}$, compondo três vistas dos ramos (Figura $1 \mathrm{H}$ ). A data de brotação de cada gema foi anotada no estádio de ponta verde (Figura 1I), correspondente ao estádio B-C da escala fenológica de Iuchi (2006). As estacas foram avaliadas por um período de 56 dias, depois de transferidas para a câmara de crescimento. Ao final do período, as gemas não brotadas foram cortadas transversalmente e a vitalidade dos tecidos dos meristemas analisada. Esse procedimento caracterizou se a gema não brotou por estar morta ou por algum outro fator. Além disso, em 2011, analisou-se a morfologia das gemas brotadas (vegetativa ou florífera).

A brotação de 436 grupos homogêneos de gemas foi avaliada, tendo cada grupo entre 6 e 20 gemas apicais e entre 8 e 186 gemas laterais, sendo a taxa de brotação ao longo do tempo acompanhada separadamente para gemas apicais e laterais. A taxa de brotação aos 35 dias após a transferência das estacas para câmara de crescimento a $25^{\circ} \mathrm{C}$ foi analisada, separadamente, para gemas apicais e laterais, por análise de variância ponderada pelo número de gemas em cada grupo, considerando no modelo, além da metodologia, o efeito de cultivar (Royal Gala x Castel Gala). Usou-se o número de horas de frio como covariável. As médias das cinco metodologias (estacas de nós isolados - NI, estacas intactas em potes - IP, estacas embaladas na horizontal - EH, estacas embaladas na vertical com brotação em água - VA, e estacas embaladas na vertical com brotação em espuma fenólica $\mathrm{VE)}$ foram comparadas com contrastes ortogonais hierárquicos $(\mathrm{NI} \quad \mathrm{x} \quad(\mathrm{IP}+\mathrm{EH}+\mathrm{VA}+\mathrm{VE}) ; \quad \mathrm{EH} \quad \mathrm{x}$ (IP+VA+VE); IP x (VA+VE); VA x VE), testados com o teste $t$, separadamente para as gemas apicais e laterais. A mortalidade das gemas foi avaliada da mesma forma, porém com um grupo de contrastes diferente $(\mathrm{VAx}(\mathrm{NI}+\mathrm{IP}+\mathrm{EH}+\mathrm{VE})$; NIx $(\mathrm{IP}+\mathrm{EH}+\mathrm{VE})$; IP x (EH+VE); EH x VE). As análises foram feitas usando o software estatístico R (2013). 
Figura 1. Formas de acondicionamento das estacas de macieira aos diferentes regimes térmicos de frio testados para superação da dormência, em câmaras incubadoras (A, B e C), e ao calor a temperatura de $25^{\circ} \mathrm{C}$, em câmaras de crescimento, para indução e avaliação da brotação (D, E, F, G, H e I). (A) Estacas de nós isolados em potes com espuma fenólica; (B) Estacas intactas plantadas em potes com espuma fenólica; (C) Estacas intactas embaladas com filme plástico; (D) Estacas intactas, plantadas em potes com espuma fenólica; (E) Estacas intactas sustentadas por uma dupla camada de tela traçada, sobreposta a um reservatório de água com lâmina de $3 \mathrm{~cm}$; (F) Estacas intactas sustentadas por uma dupla camada de tela traçada, sobreposta a uma camada de espuma fenólica de 3,75 cm; $(\mathrm{G})$ Avaliação da brotação das gemas em estacas de nós isolados; (H) Avaliação da brotação das gemas em estacas intactas; (I) Gema brotada em estádio de ponta verde.

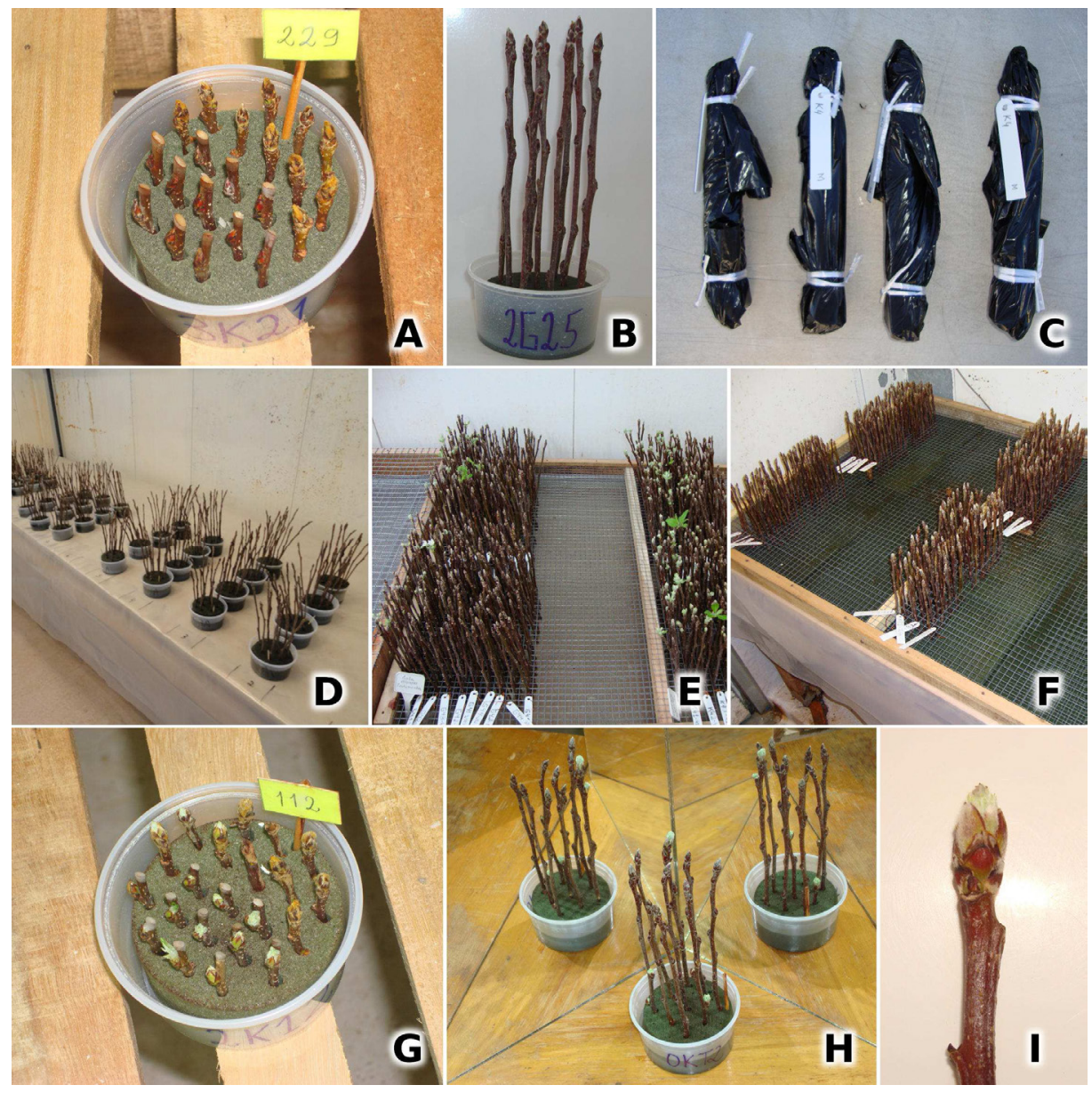

Fonte: Elaboração dos autores.

\section{Resultados e Discussão}

A evolução da brotação das gemas, sob diferentes metodologias de acondicionamento no frio, (Figura 2) dependeu do tipo de gema avaliado (laterais ou apicais). A brotação das gemas laterais (Figura 2A) foi maior $(\mathrm{P}<0,0001)$ nas estacas de nós isolados $(83,0 \%)$, que não estão sujeitas a inibições correlativas de gemas adjacentes, do que nas estacas intactas $(11,3 \%)$, em que as gemas laterais sofrem efeito da dominância apical. Em condições naturais, as gemas apicais inibem a brotação das gemas laterais pela produção e transporte polar descendente de auxinas, ocasionando restrição de brotação total e um período de brotação mais estendido (WEBSTER, 2005; HAWERROTH; PETRI, 2011). 
Figura 2. Evolução da brotação das gemas laterais (A) e apicais (B) acondicionadas ao frio em estacas de macieira de nós isolados, estacas plantadas em potes, estacas embaladas na vertical e estacas embaladas na horizontal.
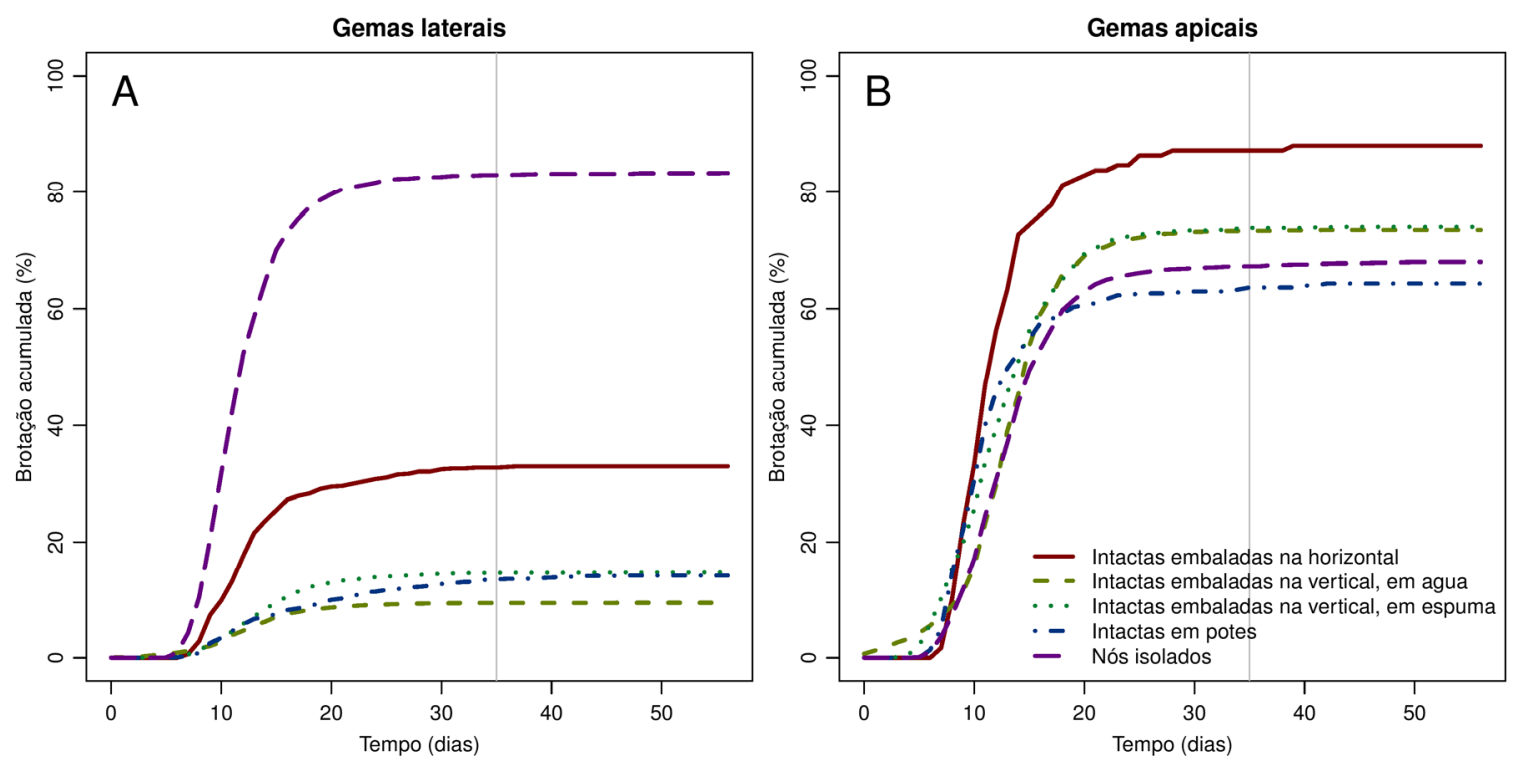

Fonte: Elaboração dos autores.

O método de estacas intactas é preferível para estudos de modelagem e predição da brotação, por manter parcialmente as inter-relações entre tecidos da planta e, consequentemente, aproximar as respostas às condições reais. Segundo Dole (2001), o método de estacas intactas é baseado no princípio da inibição correlativa que uma gema tem sobre outra, avaliando-se a paradormência e a endodormência, simultaneamente. Entretanto, quando se utilizam estacas de nós isolados, contendo uma única gema, a paradormência é eliminada, sendo avaliada apenas a endodormência (CHAMPAGNAT, 1983). A diferença de brotação observada entre as duas metodologias indica a intensidade da paradormência. Muitas metodologias de avaliação da dormência preconizam testes de nós isolados (HERTER, 1992; BALANDIER, 1992), mas, se a interação entre as gemas for expressiva, pode haver problemas na interpretação dos resultados e na avaliação das condições fisiológicas das gemas nas plantas.

Para Jackson (2003), a dormência se localiza nas gemas e as exigências em frio variam dentro de uma mesma planta, em função da localização das gemas e do estado nutricional da planta. Segundo Naor et al. (2003) e Campoy et al. (2011), as gemas laterais requerem maior quantidade de frio do que as gemas terminais. Herter (1992) também afirma que as gemas laterais de pomáceas apresentam dormência mais profunda e necessitam de maior período de frio, devido ao efeito de controle exercido pelas gemas terminais. No entanto, os resultados obtidos evidenciam que a brotação das gemas laterais é mais dependente da dominância apical (paradormência) do que do estado intrínseco de endodormência. $\mathrm{O}$ mesmo não ocorre com as gemas apicais (Figura 2B), em que a diferença na brotação entre as metodologias de nós isolados $(67,3 \%)$ e estacas intactas $(73,2 \%)$, apesar de significativa $(\mathrm{P}=0,0006)$, tem comportamento oposto e é de magnitude menor que nas laterais, o que indica que a paradormência não parece afetar as gemas apicais. Assim, o ajuste ou elaboração de modelos para a predição da brotação deve ser baseado, principalmente, nas respostas das gemas apicais, pois estas expressam melhor a endodormência (MAGUYLO; COOK; THERON, 2012).

Outros métodos podem ser utilizados para avaliação da dormência de gemas, como o uso 
de plantas inteiras ou ramos enxertados. Para Camelatto et al. (2000) e Hawerroth et al. (2010) a utilização de plantas conduzidas em vasos para estudos de dormência é limitada pela demanda de grande espaço para sua realização, elevando os custos pela necessidade de grandes câmaras de crescimento climatizadas. Além disso, durante o período de juvenilidade, que tende a variar de 3 a 5 anos (SIMÃO, 1971), não há formação de gemas florais. Trabalhos de dormência em pessegueiro com o método de "ramos enxertados" (WAGNER JUNIOR et al., 2006; CHAVARRIA; HERTER; RASEIRA, 2009) o indicam como promissor para evitar problemas de juvenilidade. O método consiste em enxertar ramos produtivos em portaenxertos previamente estabelecidos em solo ou substrato, sendo os tratamentos aplicados após a completa soldadura no ponto de enxertia. Suas vantagens são a capacidade de manter o material vegetativo por períodos mais longos do que usando ramos destacados, devido à menor desidratação e menor necessidade de espaço em relação às plantas conduzidas em vaso. Contudo, o método de enxertia ainda demanda muito espaço em relação ao método de estacas intactas, principalmente quando é necessário utilizar vários regimes térmicos.

Dentre as metodologias de estacas inteiras, o armazenamento das estacas na posição horizontal resultou em brotação das gemas laterais $(32,8 \%)$ maior $(\mathrm{P}<0,0001)$ que nas estacas incubadas na posição vertical $(10,8 \%)$. Este efeito foi menor nas gemas apicais, com diferença não significativa $(\mathrm{P}=0,14)$ na brotação entre estacas mantidas na horizontal $(87,2 \%)$ ou vertical $(72,8 \%)$. Manter as estacas deitadas quando acondicionadas ao frio pode ter reduzido o fluxo hormonal de auxinas da gema apical para as laterais, atenuando a dominância apical e proporcionando um maior potencial de brotação (Figura 2A). Os resultados reforçam a forte influência que as gemas laterais de estacas intactas eretas sofrem pela presença da gema apical, o que representa a condição natural em uma árvore de macieira, conforme salientam Hawerroth e Petri
(2011). Algumas recomendações de manejo de pomar até sugerem a prática do arqueamento de ramos de macieira (PETRI, PALLADINI; POLA, 2006) e pereira (DECKERS; SCHOOFS, 2004), para reduzir os reflexos negativos da dominância apical. Tal medida induz a diminuição do crescimento das brotações terminais, favorecendo o crescimento das gemas axilares (WEBSTER, 2005). O uso de estacas intactas mantidas na vertical corresponde à condição que mais se aproxima do estado natural das gemas em ramos de macieira, o que é importante para modelagem do processo de dormência.

Em experimentos que requerem o uso de um grande número de unidades de observação, como trabalhos de modelagem da dormência, é importante otimizar o uso do espaço físico disponível. Nos experimentos realizados, tinham-se à disposição câmaras incubadoras com espaço interno de $0,28 \mathrm{~m}^{3}$, nas quais foram acondicionadas as estacas. Usando a metodologia de estacas intactas embaladas em feixes (na posição vertical), foi possível acomodar 1400 estacas por incubadora, contra apenas 360 com o método de estacas intactas em potes. O acondicionamento de estacas intactas em espuma fenólica também proporcionou grande impacto na demanda por área física durante o período de calor em câmara de crescimento. Quando sustentadas por uma dupla camada de tela trançada sobre plataforma de água ou espuma fenólica, o potencial de avaliação simultânea foi de 1460 estacas $\mathrm{m}^{-2}$, enquanto em estacas plantadas em potes o potencial máximo foi de 860 estacas $\mathrm{m}^{-2}$.

A brotação observada em gemas laterais não diferiu significativamente $(\mathrm{P}=0,19)$ entre estacas intactas mantidas em potes $(13,5 \%)$ e as embaladas em filme plástico e mantidas na vertical $(10,7 \%)$ durante o período de frio. Em gemas apicais, esse efeito foi significativo $(\mathrm{P}=0,0002)$, sendo a brotação menor nas estacas em potes $(63,6 \%)$ do que nas embaladas (73,5\%). Sugere-se, assim, o uso de estacas intactas (para manter a interação entre gemas) embaladas em filme plástico e mantidas na posição vertical durante o período de frio, 
por ocupar melhor o espaço interno das câmaras incubadoras. Pela capacidade de processamento de gemas por unidade de tempo e espaço, este método é promissor na análise de populações e seleção de materiais contrastantes em exigência de frio hibernal, em programas de melhoramento genético. Em alguns tipos de desenhos experimentais, pode ser necessário manter as estacas em potes durante o período de frio, o que, apesar de ocupar mais espaço, não interfere no resultado final.

Durante o período de indução e avaliação da brotação a $25^{\circ} \mathrm{C}$, as estacas intactas acondicionadas em plataforma com espuma fenólica se conservaram melhor que aquelas com a sua base permanentemente imersa em água. Isto pode ser observado pela análise dos primórdios florais ou foliares das gemas (Figura 3), após a conclusão dos experimentos. As estacas mantidas em água sofreram ressecamento e morte de gemas (Figura 3A), enquanto que as estacas mantidas em espuma fenólica (Figura 3B) permaneceram saudáveis. Observou-se uma mortalidade de gemas muito maior $(\mathrm{P}<0,0001)$ em água $(75,4 \%)$ que em espuma $(8,9 \%)$. Portanto, a indução da brotação em plataforma com espuma fenólica, por promover maior longevidade dos ramos, é a forma mais indicada para avaliar o material vegetal destacado da planta, quando exposto ao calor em ambiente controlado. A espuma fenólica (ou espuma floral) é composta por fenol, formaldeído, hidrocarboneto halogenado e surfactante, possui baixa resistência à compressão, mediana dureza e densidade de 20 $\mathrm{kg} \mathrm{m}^{-3}$, sendo sua principal utilidade à absorção de água, para manutenção de plantas ou parte de plantas hidratadas por um período prolongado (CARVALHO; FROLLINI, 1999).

Para Dennis Junior (2003), o uso de estacas intactas limita o tempo de avaliação, pela curta longevidade dos ramos. Citadin, Raseira e Quezada (1998) observaram problemas de conservação de ramos destacados de pessegueiro, em diferentes substratos, mascarando o verdadeiro potencial de brotação e floração. Estacas de nós isolados apresentam maior restrição de durabilidade, mesmo quando plantadas em espuma fenólica, devido ao menor aporte de reservas, maior exposição dos tecidos internos e maior desequilíbrio hormonal, em função do etileno e ácido abscísico induzidos pelos cortes nos tecidos (DENNIS JUNIOR, 2003). Neste trabalho, observou-se que a mortalidade de estacas em nós isolados $(16,9 \%)$ foi maior $(\mathrm{P}<0,0001)$ que a de estacas intactas mantidas em espuma $(6,7 \%)$, o que reforça a recomendação de não se usar estacas de nós isolados.

Figura 3. Análise dos tecidos das gemas apicais de macieira, após 56 dias a temperatura de $25^{\circ} \mathrm{C}$, quando as estacas foram mantidas com a base imersa em água (A), em que houve ressecamento e morte de gemas, ou em espuma fenólica umedecida (B), em que as gemas permaneceram vivas.

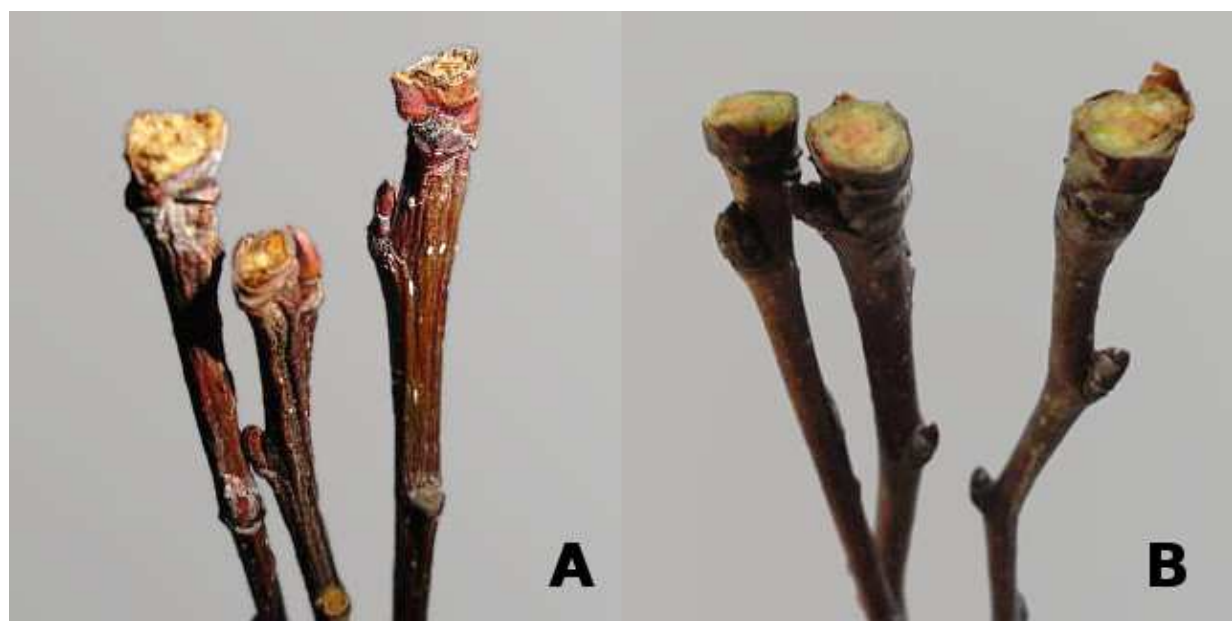

Fonte: Elaboração dos autores. 
A necessidade de corte periódico das estacas na câmara de crescimento foi dispensada quando as mesmas foram mantidas em espuma fenólica, diferentemente de quando se utilizou plataforma apenas com água. Isto ocorreu pela melhor conservação das estacas em espuma fenólica, impedindo, provavelmente, a obstrução dos feixes vasculares dos ramos. Para Amorim, Rezende e Bergamin Filho (2011) o excesso de umidade pode provocar o aparecimento de doenças, apodrecimento e morte de plantas. Nos ensaios conduzidos ficou evidente a importância da forma de acondicionamento das estacas sobre o aspecto fitossanitário. A aplicação de fungicidas foi dispensada nos anos em que o material vegetal foi desinfestado previamente com hipoclorito de sódio, sem nenhum comprometimento ou perda de estacas por doenças fúngicas. O cuidado físico com a fixação das estacas (em espuma) e com as condições sanitárias iniciais (antes do tratamento de frio) também possibilitam que o período de avaliação das estacas no calor possa ser otimizado. Durante o período de 56 dias de avaliação, ficou evidente que, até 35 dias, as gemas já demonstravam todo seu potencial de brotação, pois apenas $0,61 \%$ das gemas que brotaram o fizeram após 35 dias. Isto ressalta a importância de manter as estacas em espuma fenólica (e não em água) e a importância de uma boa desinfestação inicial para o controle fitossanitário.

Figura 4. Distribuição da brotação de gemas apicais e laterais de macieiras 'Castel Gala' e 'Royal Gala' e sua morfologia (floríferas ou vegetativas).

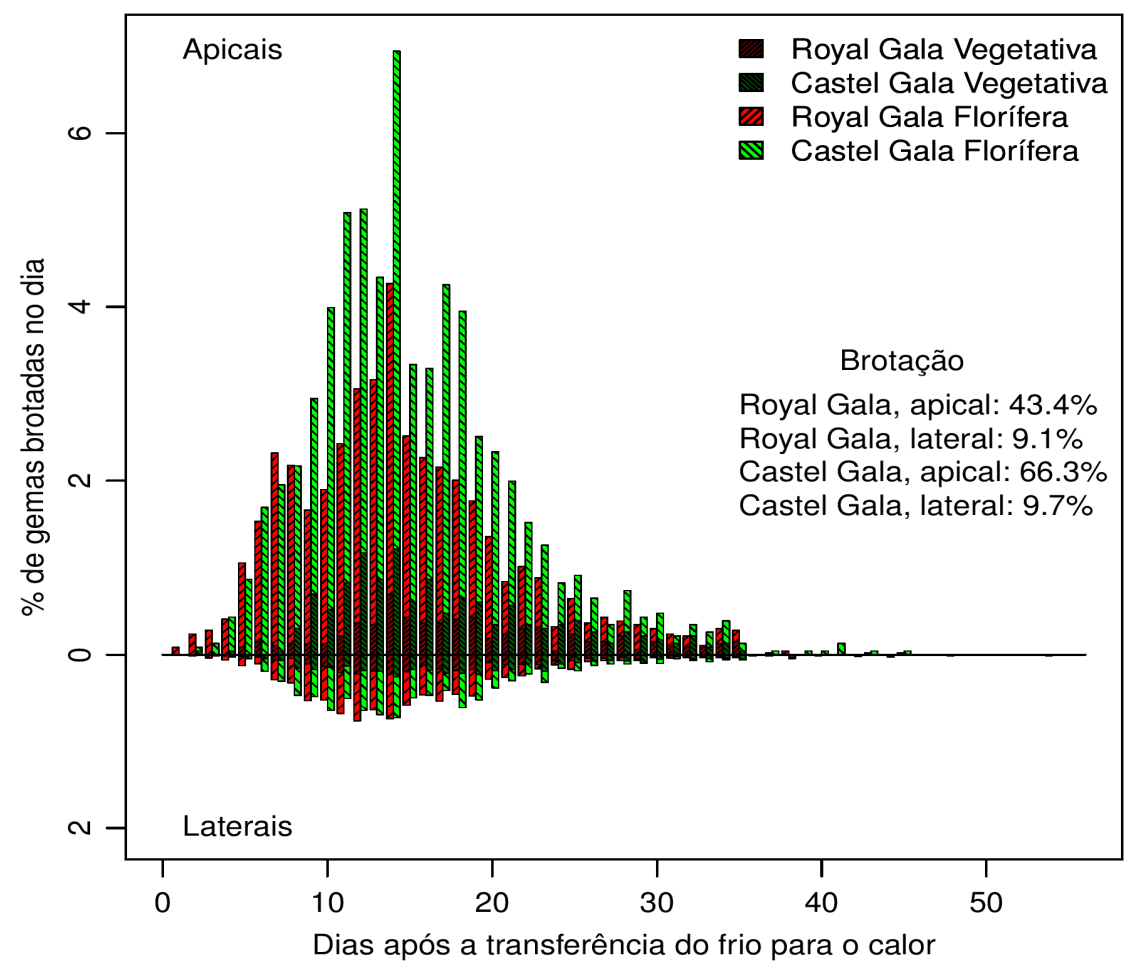

Fonte: Elaboração dos autores.

Para avaliar a brotação das gemas, apesar da fotografia ser uma forma eficaz em estacas de nós isolados, permitindo o registro do tratamento e a demarcação da brotação no tempo (para conferências futuras na análise de dados), nas estacas intactas este método não apresentou boa aplicabilidade, 
sendo difícil a visualização das gemas do ramo (principalmente das laterais). Em função disso, apesar de se dispor de um registro fenológico instantâneo, que pode ser consultado mesmo após o término do experimento, a análise das fotografias demandou um tempo extra prolongado (90 dias), em comparação ao método de inspeção visual direta e registros diários das gemas em estádio de ponta verde. Pela subjetividade na identificação do ponto exato para registro da brotação, salienta-se a importância desta avaliação ser efetuada por um grupo restrito e homogêneo de avaliadores, para evitar ou minimizar o erro experimental da análise.

Figura 5. Fluxograma para avaliação da dormência de gemas de macieira, da coleta à avaliação da brotação.

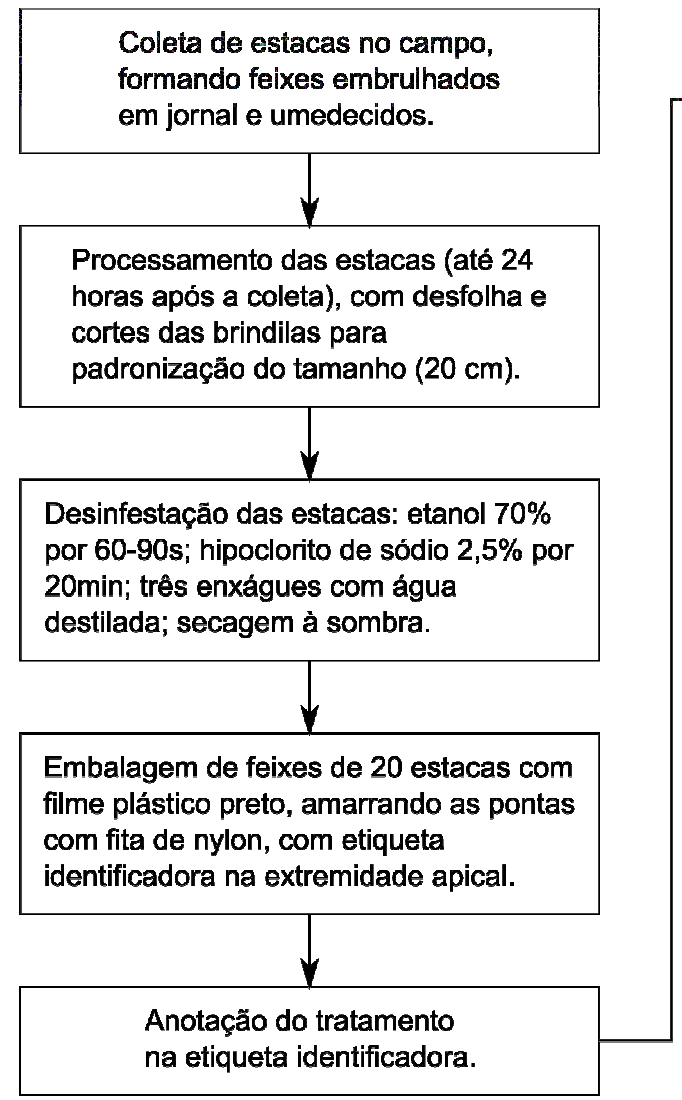

Fonte: Elaboração dos autores.

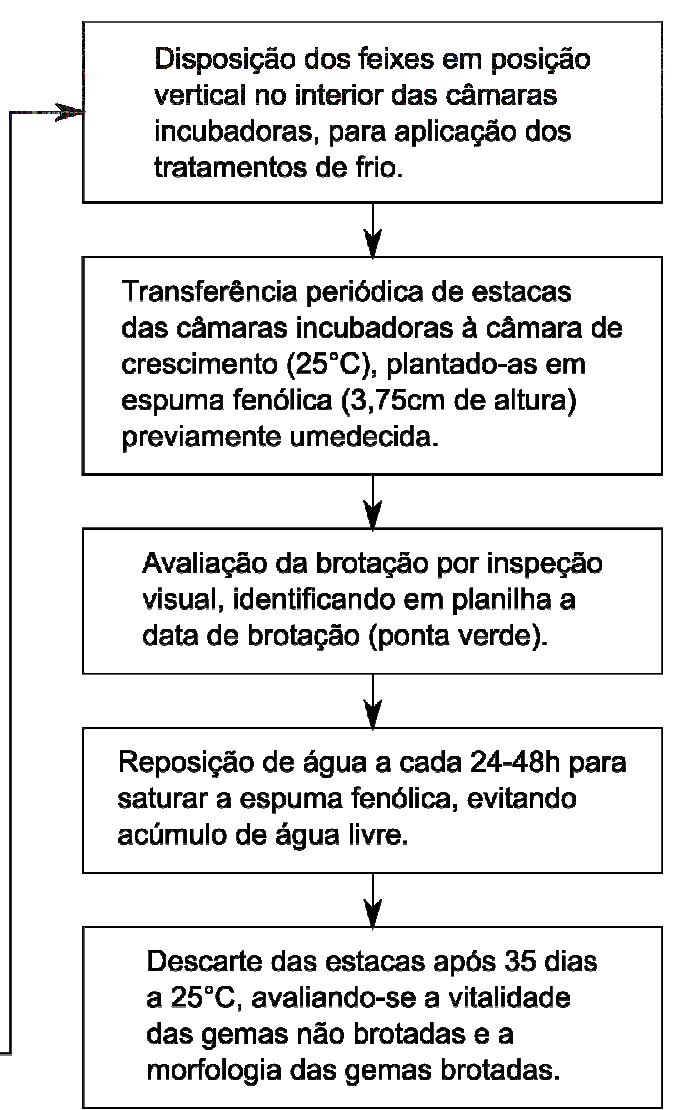

Ao final do período de avaliação da brotação, além de se avaliar a vitalidade das gemas não brotadas, a morfologia das brotadas foi verificada, permitindo classificar o tipo de gema em florífera ou vegetativa. Na Figura 4, pode-se perceber uma predominância de gemas floríferas, tanto nas gemas apicais como nas laterais, e uma brotação aparentemente mais precoce nas gemas floríferas que nas vegetativas.
Faust et al. (1995) e Naor et al. (2003) salientam que, em macieiras, as gemas floríferas apresentam menor requerimento de frio que as vegetativas, o que pode explicar sua precocidade. Apesar destes contrastes, é imprescindível considerar a posição da gema na planta para inferir sobre o comportamento de dormência e não simplesmente a morfologia da gema, já que as gemas apicais são controladas, 
principalmente, pela endodormência (MAGUYLO; COOK; THERON, 2012) e as laterais pela paradormência.

O protocolo final recomendado para o método de avaliação da dormência em gemas de macieira é apresentado na Figura 5. Salienta-se a necessidade de coleta de material de boa qualidade, uma desinfestação eficiente, o uso de estacas intactas embaladas em filme plástico e acondicionadas verticalmente na câmara incubadora, durante $o$ período de frio, e a avaliação diária da brotação em plataforma de espuma fenólica durante o período de calor, em câmara de crescimento. Apesar do método ter sido desenvolvido para macieiras, acredita-se que métodos similares possam ser utilizados em outras espécies frutíferas de clima temperado.

\section{Conclusões}

Ométodobiológico de estacas intactas, embaladas com filme plástico na posição vertical ascendente, durante os tratamentos de frio, e acondicionadas em espuma fenólica, durante a indução da brotação no calor, é um método adequado para avaliar o estado de dormência de gemas em macieiras para estudos de modelagem.

\section{Agradecimentos}

À Embrapa Uva e Vinho, à UFRGS, ao CNPq e ao produtor Décio Amorin, pela concessão do material para a elaboração do estudo.

\section{Referências}

ANDRADE, G. A.; RICE, W. C.; CARAMORI, P. H.; ZARO, G. C.; MEDINA, C. C. Zoneamento agroclimático de café robusta no Estado do Paraná e impactos das mudanças climáticas. Semina: Ciências Agrárias, Londrina, v. 33, n. 4, p. 1381-1390, 2012.

AMORIM, L.; REZENDE, J. A. M.; BERGAMIN FILHO, A. Manual de fitopatologia. 4. ed. Piracicaba: Editora Ceres, 2011. 704 p.
BALANDIER, P. Étude dynamique de la croissance et du développement des bourgeons de quelques cultivars de pêcher cultivés à diverses altitudes sous le climat tropical de l'île de La Réunion. 1992. Thèse (Doctorat Physiologie Végétale) - Université Blaise Pascal, Clermont Ferrand.

CAMELATTO, D.; NACHTIGALL, G. R.; ARRUDA, J. J. P.; HERTER, F. G. Efeito de flutuações de temperatura, horas de frio hibernal e reguladores de crescimento no abortamento floral de gemas de pereira. Revista Brasileira de Fruticultura, Jaboticabal, v. 22, n. 2, p. 111-117, 2000.

CAMPOY, J. A.; RUIZ, D.; COOK, N.; ALLDERMAN, L.; EGEA, J. High temperatures and time to budbreak in low chill apricot 'Palsteyn'. Towards a better understanding of chill and heat requeriments fulfillment. Scientia Horticulturae, Amsterdam, v. 129, n. 4, p. 649655, 2011.

CARVALHO, G.; FROLLINI, F. Lignina em espumas fenólicas. Polímeros, São Paulo, v. 9, n. 1, p. 66-75, 1999.

CHAMPAGNAT, P. Bud dormancy, correlation between organs, and morphogenesis in woody plants. Fiziologiya Rastenii, Moxow, v. 30, n. 30, p. 458-471, 1983.

CHAVARRIA, G.; HERTER, F. G.; RASEIRA, M. C. B. Effect of mild temperatures on bud breaking dormancy in low and medium chill peaches. Ciência Rural, Santa Maria, v. 39, n. 7, p. 2016-2021, 2009.

CITADIN, I.; RASEIRA, M. C. B.; QUEZADA, A. C. Substrato para conservação de ramos destacados de pessegueiro. Agropecuária Clima Temperado, Pelotas, v. 1, n. 1, p. 61-66, 1998.

CITADIN, I.; RASEIRA, M. C. B.; HERTER, F. G.; SILVA, J. B. Heat requirement for blooming and leafing in peach. HortScience, Alexandria, v. 3, n. 2, p. 305-307, 2001.

DECKERS, T.; SCHOOFS, H. Growth reduction and flower bud quality on pear trees. Acta Horticulturae, Hague, v. 636, n. 1, p. 249-258, 2004.

DENARDI, F.; SECCON, J. J. 'Castel Gala' - mutação da macieira 'Gala' com baixa necessidade de frio e maturação precoce. Revista Agropecuária Catarinense, Florianópolis, v. 18, n. 2, p. 78-82, 2005.

DENNIS JUNIOR, F. G. Problems in standardizing methods for evaluating the chilling requirements for the breaking of dormancy in buds of woody plants. HortScience, Alexandria, v. 38, n. 3, p. 347-350, 2003.

DOLE, J. Standardizing methods for evaluating the chilling requirements for the breaking of dormancy in bulbs, corms, and tubers. HortScience, Alexandria, v. 38, n. 3, p. 341-346, 2001. 
EREZ, A; FISHMAN, S. The dynamic model for rest completion in peach buds. Acta Horticulturae, Hague, v. 276, n. 1, n. 276, p. 165-174, 1990.

FAUST, M.; LIU, D.; WANG, S. Y.; STUTTE, G. W. Involvement of apical dominance in winter dormancy of apple buds. Acta Horticulturae, Hague, v. 395, n. 1, p. 47-56, 1995.

HAWERROTH, F. J. HERTER, F. G.; PETRI, J. L.; LEITE, G. B.; PEREIRA, J. F. M. Dormência em frutíferas de clima temperado. Pelotas: Embrapa Clima Temperado, 2010. 56 p. (Documentos, 310).

HAWERroth, F. J.; PETRI, J. L. Controle do desenvolvimento vegetativo em macieira e pereira. Pelotas: Embrapa Clima Temperado, 2011. 35 p. (Documentos, 147).

HERTER, F. G. Dormance des bourgeons et phenologie des quelques cultivars de pommier: effet de la température em interaction avec le génotype. 1992. Thèse (Doctorat Physiologie Végétale) - Université Blaise Pascal, Clermont Ferrand.

IUCHI, V. L. Botânica e fisiologia. In: EPAGRI. A cultura da macieira. Florianópolis: Epagri, 2006. p. 59-104.

JACKSON, J. E. The shoot system. In: JACKSON, J. E. Biology of apples and pears. Cambridge: Cambridge University Press, 2003. p. 157-211.

LANG, G. A. EARLY, J. D.; MARTIN, G. C.; DARNELL, R. L. Endo-, para- and ecodormancy: physiological terminology and classification for dormancy research. Hortscience, Alexandria, v. 22, n. 3, p. 371-178, 1987.

MAGUYLO, K.; COOK, N. C.; THERON, K. I. Environment and position of first bud to break on apple shoots affects lateral outgrowth. Trees, Heidelberg, v. 26, n. 2, p. 663-675, 2012.
NAOR, A.; FLAISHMAN, M.; STERN, R.; MOSHE, A.; EREZ, A. Temperature effects on dormancy completion of vegetative buds in apple. Journal of the American Society for Horticultural Science, Mount Vermon, v. 128, n. 5, p. 636-641, 2003.

PETRI, J. L.; PALladini, L. A.; POlA, A. C. Dormência e indução da brotação da macieira. In: EPAGRI. A cultura da macieira. Florianópolis: Epagri, 2006. $743 \mathrm{p}$.

R CORE TEAM. $R$ : a language and environment for statistical computing. R Foundation for Statistical Computing. Vienna: Austria, 2013. Disponível em: $<$ http://www.R-project.org/>. Acesso em: 30 jul. 2013.

RICHARDSON, E. A.; SEELEY, S. D.; WALKER, D. R. A model for estimating the completion of rest for Redhaven and Elberta peach trees. HortScience, Alexandria, v. 9, n. 4, p. 331-332, 1974.

SHALTOUT, A. D.; UNRATH, C. R. Rest completion prediction model for 'Starkrimson Delicious' apples. Journal of the American Society for Horticultural Science, Mount Vermon, v. 108, n. 6, p. 957-961, 1983.

SIMÃO, S. Manual de fruticultura.São Paulo: Editora Agronômica Ceres, 1971.530 p.

WAGNER JUNIOR, A.; BRUCKNER, C. H.; PIMENTEL, L. D.; RASEIRA, M. C. B. Evaluation of chilling requirement in peach through grafted twigs. Acta Horticulturae, Hague, v. 713, n. 1, p. 243-246, 2006.

WEBSTER, A. D. Shoot growth. In: TROMP, J.; WEBSTER, A. D.; WERTHEIM, S. J. Fundamentals of temperate zone tree fruit production. The Netherlands: Backhuys Publishers, 2005. p. 120-135.

WEINBERGER, J. H. Chilling requirements of peach varieties. Proceedings of the American Society for Horticultural Science, Geneva, v. 56, n. 1, p. 122-128, 1950. 
